\title{
OBTENÇÃO DO 2-ETÓXI-2-METILPROPANO GRAU ANALÍTICO A PARTIR DO PRODUTO COMERCIAL
}

\author{
Vanessa Venturi* e Renato Cataluña \\ Departamento de Físico-Química, Instituto de Química, Universidade Federal do Rio Grande do Sul, Av. Bento Gonçalves, 9500 , \\ 91501-970 Porto Alegre - RS, Brasil
}

Recebido em 7/7/09; aceito em 14/10/09; publicado na web em 25/2/10

\begin{abstract}
PRODUCTION OF ANALYTICAL GRADE 2-ETHOXY-2-METHYLPROPANE FROM A COMMERCIAL PRODUCT.Ethyl tert-butyl ether (ETBE) is produced by commercial processes to a purity of up to $96 \%$. In recent years, several companies have started to produce ETBE, increasing the demand for standards with higher grades of purity in the area of production control and final product certification. The present work involved the development of a purification protocol for obtaining high purity ETBE from the commercial product used in the formulation of automotive gasolines, using a spinning band distillation column. The ETBE thus produced showed a purity of over $99.5 \%$, its main contaminant being its isomer, ethyl-sec-butyl ether (ESBE).
\end{abstract}

Keywords: ETBE; purification; spinning band distillation.

\section{INTRODUÇÃOO}

A partir da retirada dos aditivos antidetonantes de alquil-chumbo da gasolina, devido a questões ambientais e de saúde pública, foi iniciada a utilização de compostos oxigenados, os quais, além de elevarem a octanagem das gasolinas, reduzem as emissões de compostos poluentes. ${ }^{1,2} \mathrm{O}$ 2-metóxi-2-metilpropano (MTBE) foi largamente utilizado como aditivo oxigenado para reduzir as emissões de contaminantes devido, principalmente, aos aspectos econômicos favoráveis à sua produção. Porém, a ocorrência de contaminações em lençóis freáticos decorrentes de vazamentos de MTBE e sua alta miscibilidade em água deram início a sua substituição, especialmente na Europa, pelo 2-etóxi-2-metilpropano (ETBE), que tem uma fração de biocombustível mais elevada, é menos miscível em água e mais atrativo em termos de rendimento térmico. ${ }^{1-5}$ Diversas plantas produtoras de MTBE já foram convertidas para produzir ETBE. Devido à disponibilidade e preços competitivos do etanol no mercado brasileiro, o ETBE se torna um produto promissor, apesar de ter um preço mais elevado que o MTBE para exportação., ${ }^{2,3}$ Mesmo com essas vantagens, o ETBE ainda não é utilizado no mercado interno, devido à preferência e facilidade nacional pelo consumo do etanol.

Muitos compostos oxigenados utilizados em larga escala na formulação de gasolinas automotivas também fazem parte de uma segunda classificação, a dos biocombustíveis, dentre os quais podemos destacar o etanol, produzido no Brasil principalmente a partir da cana-de-açúcar, e o isobutanol, obtido a partir da fermentação de carboidratos. Outros compostos oxigenados, como o 2-etóxi 2-metil propano (ETBE) e o 1-etóxi 1,1-dimetil propano (TAEE), são compostos considerados parcialmente biocombustíveis uma vez que são produzidos a partir reação do etanol, provindo da biomassa, com o isobuteno ou isoamilenos, respectivamente. A porcentagem mássica de biocombustível do ETBE é de $45 \%$, enquanto que para o TAEE é de $40 \%$.

O ETBE é sintetizado a partir do isobuteno e do etanol, utilizando uma resina de troca iônica ácida. ${ }^{6,7}$ As principais reações secundárias são a dimerização e a hidratação do isobuteno, as quais podem ser minimizadas utilizando-se excesso de etanol e reagentes isentos de água, respectivamente. ${ }^{8,9}$ A pureza de especificação para exportação do ETBE é de $96 \%$, sendo perfeitamente atendida pelos processos convencionais

*e-mail: vanessa.venturi@gmail.com utilizados nas plantas atualmente em operação. Para certificação final do produto e calibração dos equipamentos, são necessários padrões com elevada pureza, a fim de calibrar e validar os equipamentos e metodologias necessárias. Esses padrões possuem custo elevado e despendem muito tempo para serem adquiridos no mercado internacional.

A utilização de colunas de banda rotatória tem sido amplamente empregada em laboratório para purificação de compostos a partir da diferença no ponto de ebulição. Esse sistema auxilia a dispersão líquido/vapor, promovendo alta eficiência, com grande número de pratos teóricos em pequenas dimensões. Geralmente, as bandas rotatórias incorporadas dentro dessas colunas de destilação são de forma espiral e possuem ampla seção transversal, ao ponto de praticamente rasparem as paredes da coluna quando postas em rotação. ${ }^{10-12}$ Devido a esse fator, as bandas rotatórias podem ser de teflon ou metal, sendo o teflon mais utilizado devido ao menor atrito. Porém, para destilações com temperatura de vapor acima de $225^{\circ} \mathrm{C}$, as bandas de metal são preferidas, pois as bandas de teflon podem se tornar maleáveis. Dependendo do líquido a ser destilado e do número de rotações da banda rotatória (velocidade ótima de $2000 \mathrm{rpm}$ ), pode-se alcançar até 50 estágios teóricos em baixa pressão. ${ }^{13}$

O desenvolvimento de uma rota de purificação simples e eficiente possibilita a viabilidade tecnológica para obtenção de um produto com um mínimo de 99,0\% de pureza, competitivo com os similares obtidos no mercado externo. O presente trabalho teve como objetivo obter um protocolo analítico com o mínimo de operações intermediárias, máxima pureza e identificação dos contaminantes, capaz de fornecer ETBE com alto grau de pureza, partindo-se de um produto comercial utilizado na formulação de gasolinas automotivas.

\section{PARTE EXPERIMENTAL}

\section{Materiais}

O ETBE com alto grau de pureza foi obtido a partir do produto comercial utilizado nas formulações de gasolinas automotivas. O padrão certificado White Martins, utilizado para identificação e obtenção dos fatores de resposta, contém os seguintes componentes: etanol, 1-buteno, 2-metil 2-propanol (TBA), 2-etóxi 2-metilpropano (ETBE), 2-butanol (SBA) e 2,2,4- trimetilpentano (di-isobutileno - DIB's). Todos os componentes foram identificados até uma concentração mínima de $0,01 \%$ massa. 


\section{Caracterização}

A caracterização das frações obtidas nas diferentes etapas do processo de purificação foi realizada por cromatografia gasosa com detector de ionização em chama (FID), modelo 6890N da marca Agilent, equipado com uma coluna capilar DB-1701 (14\% cianopropilfenil-metilpolissiloxano), com $60 \mathrm{~m}$ de comprimento, $0,25 \mathrm{~mm}$ de d.i. e 0,25 $\mu \mathrm{m}$ de espessura de filme. Adicionalmente, para identificação dos componentes, utilizou-se um cromatógrafo gasoso com detector de massas (GC-MS), modelo 6890 plus da marca Agilent, equipado com uma coluna capilar HP-1 (metil-siloxano), com $100 \mathrm{~m}$ de comprimento, $0,25 \mathrm{~mm}$ de d.i. e $0,5 \mu \mathrm{m}$ de espessura de filme. Os gases utilizados na cromatografia foram nitrogênio, com pureza de $99,996 \%$ vol. como gás de arraste; hidrogênio, com pureza de 99,995\% vol. como gás combustível; e ar sintético como gás oxidante. A quantificação da água na faixa de concentração de 10 a 25000 ppm massa foi obtida através do método Karl Fischer coulométrico utilizando-se um equipamento com titulador automático modelo 758KF Metrohm ${ }^{\circledR}$, seguindo a norma ASTM D6304-04. ${ }^{14}$

\section{Processos de purificação}

A purificação do ETBE comercial foi realizada por extração e destilação. No processo de extração foi utilizada uma pera de separação com capacidade de 2,0 L, mesa agitadora orbital modelo Marconi $141^{\circledR}$, provetas graduadas de $500 \mathrm{~mL}$ e água desmineralizada.

A purificação da fração orgânica resultante do processo de extração dos alcoóis com água foi realizada por destilação diferencial utilizando uma coluna equipada com um balão de refervimento com capacidade máxima de 5,0 L e banda de rotatória de teflon controlada por um motor P/N5 FT35 seguindo a norma ASTM D 2892 - 03a. ${ }^{15}$

Para as medidas das temperaturas de topo e de fundo da coluna utilizaram-se termopares tipo PRT (platina). A condensação e o recolhimento do produto de topo da coluna foram realizados através de um banho de resfriamento na temperatura de $-5^{\circ} \mathrm{C}$ com recolhimento do condensado em provetas graduadas, e o controle do refluxo para coluna foi efetuado utilizando-se uma válvula com solenoide controlada eletronicamente. A banda rotatória utilizada neste trabalho disponibiliza 15 pratos teóricos para um refluxo volumétrico de 5:1. A coluna é revestida de isolante térmico espelhado, contendo anéis de expansão próximos à base com uma janela de visualização do gotejamento para controle do refluxo.

\section{RESULTADOS E DISCUSSÃO}

Os principais contaminantes do ETBE comercial são etanol, $\mathrm{C}_{4}$ 's, $\mathrm{C}_{5}$ 's, TBA, ESBE, DIB's e água. A retirada dos alcoóis por destilação simples é praticamente impossível devido às proximidades dos pontos de ebulição. Dessa forma, para a obtenção de um produto com alto grau de pureza, é necessária a extração dos alcoóis utilizando água como solvente extrator.

\section{Processo de extração}

Foram utilizados $20 \mathrm{~L}$ de ETBE comercial com alto grau de contaminantes resultantes da etapa inicial do processo de produção, obtida após a conversão da unidade de MTBE para produção de ETBE, observando-se uma contaminação com MTBE. Esse produto com alto grau de contaminantes foi selecionado de modo a otimizar o processo de purificação para obtenção do ETBE com alto grau de pureza.

O principal contaminante do ETBE comercial é o etanol utilizado como reagente no processo de produção. Durante o processo de produção o ETBE e o etanol formam uma mistura azeotrópica, sendo realizada a purificação dos produtos de reação através da destilação extrativa com água para separação da mistura azeotrópica, observando-se uma contaminação com água e álcool no produto final devido à limitação do número de estágios da coluna de destilação. A obtenção de um produto com maior grau de pureza aumenta os custos de produção inviabilizando a comercialização do produto para formulação de gasolinas automotivas.

A primeira etapa para a obtenção de ETBE com alto grau de pureza foi realizada através da extração do etanol com água. Juntamente com o etanol foram extraídos outros alcoóis contaminantes, tais como TBA e SBA. Para definir a melhor relação de proporção ETBE/água para obtenção de menor quantidade de alcoóis no ETBE lavado, foram testadas as proporções volumétricas de 1:1, 2:1 e 3:1 água/ETBE, com três extrações consecutivas. As proporções de 1:1 e 3:1 apresentaram um percentual de extração na quantidade de alcoóis menor que 50\%, enquanto que a relação $2: 1$ apresentou variação superior a $70 \%$.

As composições das fases resultantes do processo de extração estão indicadas na Tabela 1 .

Tabela 1. Composições das fases em equilíbrio no sistema bifásico de extração

\begin{tabular}{lccc}
\hline $\begin{array}{l}\text { Relação de extração } \\
\text { (volume) }\end{array}$ & Componentes & $\begin{array}{c}\text { Composição } \\
\text { fase orgânica } \\
\text { ( volumétrica dos } \\
\text { componentes) }\end{array}$ & $\begin{array}{c}\text { Composição } \\
\text { fase aquosa } \\
\text { \% volumétrica dos } \\
\text { componentes) }\end{array}$ \\
\hline \multirow{4}{*}{$1: 1$} & Água & 0.34 & 98.20 \\
& ETBE & 96.48 & $<0.01$ \\
$2: 1$ & Alcoóis & 2.58 & 1.79 \\
& Água & 0.35 & 97.61 \\
& ETBE & 98.93 & 0.28 \\
$3: 1$ & Alcoóis & 0.08 & 2.10 \\
& Água & 0.36 & 97.74 \\
\hline
\end{tabular}

Os componentes que mais se destacam pela variação da concentração, na proporção de 2:1, são: metanol (redução de 93\%), etanol (redução de 99\%), TBA (redução de 99\%), SBA (redução de 98\%), TAME (redução de $92 \%$ ), e a água (aumento de $220 \%$, atingindo sua saturação máxima no produto).

A partir dos resultados apresentados na Tabela 1, observa-se que a relação 2:1 apresenta a menor concentração de alcoóis na fase orgânica. Tendo em vista o menor número de operações para purificação, foi utilizada a relação de 2:1 de água/ETBE, e um tempo de agitação de 2 min sob rotação de 8 rpm em mesa agitadora orbital.

\section{Processo de destilação}

A extração dos alcoóis com solvente provoca uma saturação do produto com a água, a qual irá auxiliar no processo de purificação por destilação com banda rotatória formando uma mistura com menor ponto de ebulição, que auxilia na remoção dos compostos leves de baixo ponto de ebulição. Destilações convencionais geralmente utilizam colunas recheadas, dotadas de um material de empacotamento dentro da coluna de destilação, com o objetivo de aumentar a área superficial líquido/vapor. Uma forma de aumentar a eficiência do processo de destilação é a utilização de uma coluna com banda rotatória, obtendo, assim, um melhor contato líquido/vapor, aumentando o número de estágios teóricos.

Ensaios preliminares de destilação, utilizando $300 \mathrm{~mL}$ do ET$\mathrm{BE}_{\text {hidratado }}$ recolhendo-se alíquotas de aproximadamente $10 \mathrm{~mL}$ de destilado, forneceram as composições mássicas necessárias para 
estimar as melhores faixas de corte para as frações subsequentes.

A fração com maior grau de pureza obtida na primeira etapa de destilação, denominada $\mathrm{ETBE}_{\text {destilado }}$, exclui as alíquotas referentes à fração com os componentes leves e água, que representam $35 \%$ da massa inicial. A fração que permaneceu no fundo da coluna, juntamente com os componentes de maior ponto de ebulição, representa $13 \%$ da massa inicial, sendo então recolhidos $48 \%$ da massa inicial na forma de $\mathrm{ETBE}_{\text {destilado }}$ Observando-se o comportamento deste primeiro estágio de destilação, percebe-se que as primeiras frações retiraram, juntamente com o $\mathrm{C}_{4}$, uma grande quantidade de ETBE, já sendo observada a presença de ESBE. As frações de 35 a $48 \%$ em massa de destilado apresentam uma redução significativa da quantidade de $\mathrm{C}_{4}$, porém, a quantidade de ESBE começa a aumentar no produto de topo. No início da destilação, a água evapora juntamente com os compostos leves, permanecendo vapor no sistema até aproximadamente $30 \%$ em massa recolhida nas condições apresentadas. Foram realizadas outras destilações do $\mathrm{ETBE}_{\text {hidratado }}$, correspondentes ao primeiro estágio de destilação, obtendo-se volume suficiente de ETBE $_{\text {destilado }}$ para um segundo estágio de destilação, com objetivo de reduzir a quantidade de água e de ESBE. A Figura 1 esquematiza o processo de purificação proposto discriminando as correntes resultantes de cada etapa.

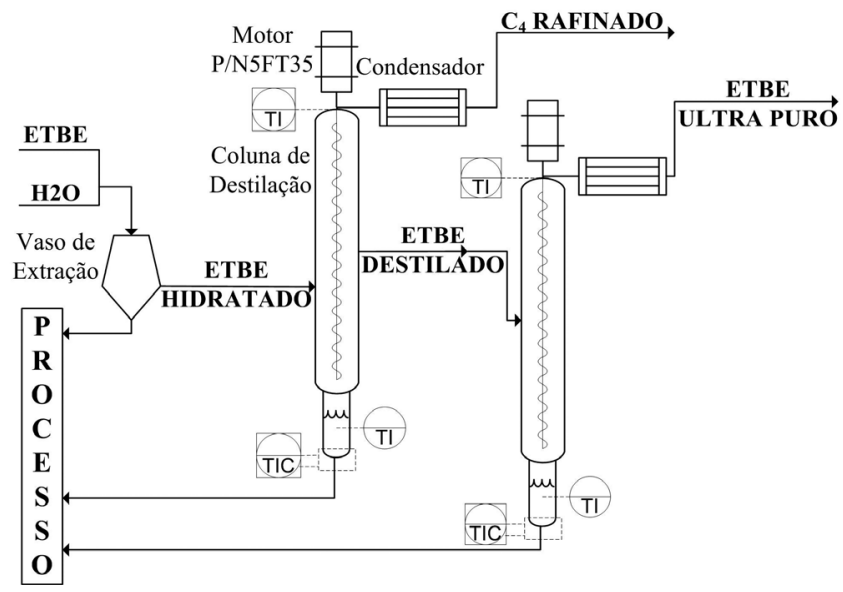

Figura 1. Fluxograma do processo de purificação utilizado $;$ TIC = controlador e indicador de temperatura, $T I=$ indicador de temperatura

O recolhimento de pequenas alíquotas de $10 \mathrm{~mL}$ também foi utilizado para determinar as frações de corte para obtenção do ETBE com alto grau de pureza denominado $\mathrm{ETBE}_{\text {ultra puro, }}$ a partir do $\mathrm{ETBE}_{\text {destilado }}$ como carga do segundo estágio de destilação. A fração volumétrica com maior grau de pureza foi obtida separando $60 \%$ da massa inicial como produto de topo e $28 \%$ em massa da carga como produto de fundo. Os $10 \%$ restantes da massa inicial, com composição apresentada na Tabela 2, representa a fração mais nobre do processo de purificação, obtendo-se ETBE com 99,90\% de pureza e 300 ppm de água.

Na Tabela 2, os resultados de cromatografia gasosa e Karl Fischer foram normalizados para introduzir a água na composição destes pontos, e o rendimento corresponde à porcentagem mássica de produto especificado, obtido em cada etapa de purificação, tendo como base a massa inicial das respectivas cargas.

Na Tabela 2, pode-se verificar que, ao final do primeiro estágio de destilação, resultando no $\mathrm{ETBE}_{\text {destiado }}$, obtém-se $46 \%$ em massa de produto com $99,5 \%$ em massa de pureza a partir do produto com baixos níveis de alcoóis, resultante do processo de extração $\left(\mathrm{ETBE}_{\text {hidratado }}\right)$. O grau de pureza de $99,5 \%$ já é considerado adequado para utilização como padrão. Para obtenção de ETBE com alto grau de pureza, ET$\mathrm{BE}_{\text {ultra puro }}$, foi utilizado um segundo estágio de destilação, capaz de
Tabela 2. Concentrações percentuais mássicas e rendimento global das etapas de purificação

\begin{tabular}{lcccc}
\hline Contaminante & $\begin{array}{c}\text { ETBE } \\
\text { Produto }\end{array}$ & $\begin{array}{c}\text { ETBE } \\
\text { Hidratado }\end{array}$ & $\begin{array}{c}\text { ETBE } \\
\text { Destilado }\end{array}$ & $\begin{array}{c}\text { ETBE } \\
\text { Ultrapuro }\end{array}$ \\
\hline C $_{4}$ s & 0,213 & 0,214 & 0,031 & 0,015 \\
Metanol & 0,071 & 0,005 & 0,004 & 0,000 \\
C $_{5}$ 's & 0,102 & 0,178 & 0,009 & 0,002 \\
Etanol & 3,343 & 0,020 & 0,030 & 0,010 \\
MTBE & 0,052 & 0,042 & 0,021 & 0,001 \\
TBA & 0,843 & 0,006 & 0,007 & 0,006 \\
ESBE & 0,128 & 0,144 & 0,158 & 0,017 \\
SBA & 0,050 & 0,001 & 0,003 & 0,001 \\
TAME & 0,004 & 0,000 & 0,000 & 0,000 \\
DIB & 0,038 & 0,044 & 0,014 & 0,000 \\
TAEE & 0,033 & 0,038 & 0,007 & 0,000 \\
DIB & 0,148 & 0,183 & 0,018 & 0,002 \\
ETBE & 94,823 & 98,633 & 99,518 & 99,918 \\
Água & 0,154 & 0,493 & 0,181 & 0,023 \\
Rendimento & & $95,61 \%$ & $46,27 \%$ & $10,33 \%$ \\
\hline
\end{tabular}

fornecer ETBE com 99,90\% massa de pureza, porém com um baixo rendimento, correspondente a $10 \%$ massa partindo-se do $\mathrm{ETBE}_{\text {destilado }}, \mathrm{O}$ que corresponde a aproximadamente $5 \%$ em massa do produto inicial.

Uma vez definida a viabilidade técnica do processo de purificação para obtenção do ETBE com alto grau de pureza a partir do produto comercial, procedeu-se a uma análise econômica do processo, levando em consideração as condições operacionais e de implantação. Estimou-se que o custo de produção do ETBE destilado com $99,5 \%$ de pureza é de U\$ 1,3/g, enquanto que o preço de ETBE com 99,0\% de pureza no mercado externo é de U\$ 8,9/g. O custo de produção estimado para o ETBE com 99,95\% de pureza situa-se na faixa de U\$ 5/g, o aumento do custo de produção para o ETBE com 99,95\% deve-se ao baixo rendimento da destilação, entretanto, não acarreta em um aumento significativo, uma vez que é necessária apenas uma nova operação de destilação e as frações de topo e de fundo podem ser direcionadas para ETBE com 99,5\%.

\section{CONCLUSÕES}

A obtenção de $\mathrm{ETBE}_{\text {ultra puro }}$ com pureza mínima de $99,90 \%$ a partir do produto comercial com $96 \%$ de pureza é possível utilizando-se uma extração dos alcoóis com água e destilando a fase orgânica $\left(\mathrm{ETBE}_{\text {hidratado }}\right)$ em uma coluna de banda rotatória de alta performance.

O principal contaminante do ETBE com alto grau de pureza é o ESBE, que é um isômero do ETBE. A separação do ESBE do ETBE por destilação simples é muito difícil, devido à proximidade dos pontos de ebulição destes isômeros. A extração com água dos alcoóis não é um fator crítico na pureza do ETBE, uma vez que a água é facilmente removida através da destilação.

A obtenção de ETBE com pureza de $99,5 \%$ a partir de produto comercial preenche uma lacuna no suprimento de padrões no mercado nacional, permitindo a utilização deste composto com baixo custo de produção para a pesquisa e para o desenvolvimento. A partir do produto com alto grau de pureza é possível avaliar com maior precisão suas propriedades físico-químicas, dando abertura à descoberta de outras utilizações para o produto.

\section{AGRADECIMENTOS}

À Braskem UNIB-RS pelo auxílio tecnológico e doação das amostras. 


\section{REFERÊNCIAS}

1. Cataluña, R.; da Silva, R.; de Menezes, E. W.; Ivanov, R. B.; Fuel 2008, 87,3362 .

2. Ancillotti, F.; Fattore, V.; Fuel Process. Technol. 1998, 57, 163.

3. Parlamento Europeu e Conselho da União Europeia; Jornal Oficial da União Europeia, Directiva n ${ }^{\circ}$ 30, Artigo $2^{\circ}, 8$ de maio de 2003.

4. Piel, W. J.; Fuel Process. Technol. 2001, 71, 167.

5. Braids, O. C.; Environmental Forensics 2001, 2, 189.

6. Tau, L. M.; Davis, B. H.; Appl. Catal. 1989, 53, 263.

7. Vlasenko, N. V.; Kochkin, Y. N.; Topka, A. V.; Strizhak, P. E.; Appl. Catal., A 2009, 362, 82.

8. Brockwell, H. L.; Sarathy, P. R.; Trotta, R.; Hydrocarbon Processing 1991, 133.
9. Yuan, H.; Master Thesis, Linköpings Universitet, Sweden, 2006.

10. Mayo, D. W.; Pike, R. M.; Hinkle, R. J.; US pat. 4,770,746 1988.

11. Roark, S.; Roger, R.; US pat. 5,472,574 1995.

12. Roark, S.; Roger, R.; US pat. 5,603,809 1997.

13. http://www.brinstrument.com/fractional-distillation/spinning_band_ distillation. html, acessada em Março 2009.

14. American Society for Testing and Materials; Standard Test Method for Determination of Water in Petroleum Products, Lubricating Oils, and Additives by Coulometric Karl Fischer Titration, D6304-04, West Conshohocken, PA. USA, 2004.

15. American Society for Testing and Materials; Standard Test Method for Distillation of Crude Petroleum (15-Theoretical Plate Column), D 289203a, West Conshohocken, PA. USA, 2003. 